\title{
THE PATHOGENESIS OF SENDAI VIRUS INFECTION IN THE MOUSE LUNG
}

\author{
T. W. E. Robinson, R. J. R. CURETon AND \\ R. B. HeATH \\ Departments of Bacteriology and Pathology, \\ St Bartholomew's Hospital, London
}

\section{Plates V-VII}

INFLUENZA virus infection of the mouse lung has been extensively studied for many years (Andrewes, Laidlaw and Smith, 1934; Stuart-Harris, 1965). In general it has been found that newly isolated strains of this virus rarely produce illness when inoculated into the lungs of mice, although virus replication occurs. However, after serial passage, the virus frequently produces consolidation of the lung and this results in severe illness and death. It has been suggested that this adaptation to the mouse lung is partly dependent on the selection of virus particles that are resistant to $\beta$-inhibitor (Briody, Cassell and Medill, 1955).

Parainfluenza viruses have in general not been shown to be pathogenic for laboratory animals, although Sendai virus has been shown to damage the bronchial mucous membrane of mice (Fukumi, Nishikawa and Kitayama, 1954), and other viruses in the group have been shown to cause silent infections in several species (Cook et al., 1959; Craighead, Cook and Chanock, 1960). The present report describes the histological, virological and other changes occurring in mice infected intranasally with the Sendai strain of parainfluenza virus.

\section{MATERIALS AND METHODS}

Virus. The Sendai strain of Parainfluenza type-1 virus was used. It was propagated in the allantoic cavity of 10-day-old embryonated hens' eggs.

Infection of mice. Swiss albino mice of $20-25 \mathrm{~g}$ were used. Before each experiment, serum samples were obtained from a proportion of these animals and tested to exclude the presence of antibodies against the infecting virus.

The mice were anaesthetised with ether and $0.03 \mathrm{ml}$ of virus suspension diluted in brothsaline to contain approximately $10^{5}$ EID 50 per $\mathrm{ml}$ was inoculated intranasally.

At various intervals after infection, groups of from 3 to 6 mice were killed. Their lungs were removed, weighed and then either immersed in formol-saline for histological examination, or immersed in tissue-culture medium and stored frozen at $-70^{\circ} \mathrm{C}$ for subsequent assay of virus and interferon. Blood was also taken at this time for the white cell count and for assay of serum antibody.

Histology. Sections were stained with haematoxylin and eosin as a routine and, as required, with Weigert's elastin stain, Van Gieson's stain, a modified Unna Pappenheim's stain, and by Lendrum's picro-Mallory method and the periodic acid-Schiff (PAS) procedure.

Virus assay. Lung suspensions ( 10 per cent. $w / v$ in tissue-culture medium) were prepared, and assayed for virus content in monkey kidney tissue cultures. Virus was detected in these

Received 28 Dec. 1967; accepted 22 Jan. 1968.

J. MED. MICROBIOL.—VOL. 1 (1968) 
cultures by the haemadsorption technique. Titres were calculated by the method of Reed and Muench (1938) and were expressed as TCD50 per ml of lung suspension.

Interferon assay. Lung suspensions were first ultracentrifuged $\left(77 \times 10^{3} \mathrm{~g}\right)$ for $90 \mathrm{~min}$. and were then dialysed against Sörensen's sodium citrate buffer $(p \mathrm{H} 2 \cdot 2)$ for $24 \mathrm{hr}$. The $p \mathrm{H}$ was then returned to normal by further dialysis against Earle's balanced salt solution. The samples were assayed for interferon by measuring their capacity to protect mouse " $L$ ", cells against the cytopathogenic effect (CPE) of vesicular stomatitis virus. The interferon titre was taken as the reciprocal of the highest dilution of the lung suspension that protected 50 per cent. of the cell sheet.

Antibody assay. Sera were collected from groups of 3-6 mice at various times after infection and pooled. The antibody titres of these sera and also of the lung suspensions were estimated by means of the haemagglutination-inhibition (HI) method in Takatsy microplates.

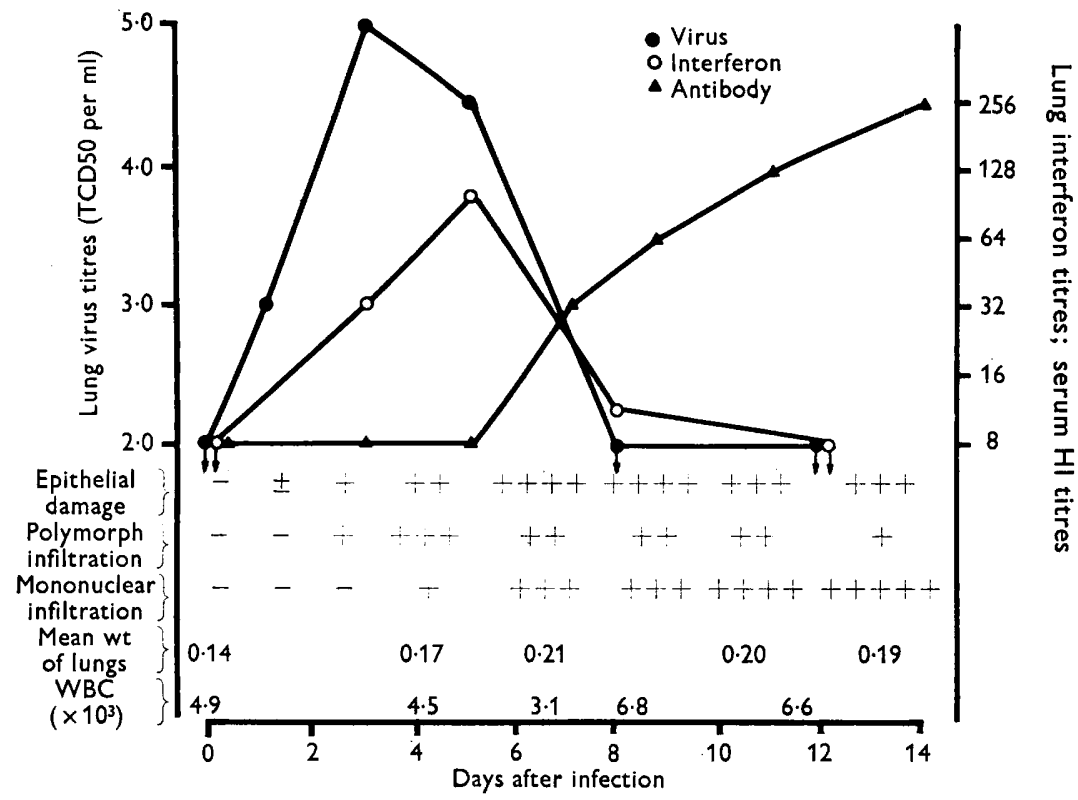

FIG. 1.-Sequence of events observed after infection of mice with Sendai virus.

$-=$ Nil detected;,,,,,$\pm+++++++++++++++=$ increasing amounts observed; $\bullet \stackrel{O}{\downarrow}=$ no activity detected at the indicated concentration.

\section{RESULTS}

Groups of mice were infected by intranasal inoculation of Sendai virus and at varying intervals after infection small numbers were killed and observations were made on (i) the general health of the mice including macroscopic changes occurring in the lungs, (ii) histological changes in the lungs, (iii) virus growth in the lungs, (iv) interferon production in the lungs, (v) antibody content of serum and lung tissue, and (vi) white blood cell counts.

\section{Macroscopic changes}

In none of the experiments that have been carried out has the virus produced any obvious clinical illness in the animals and only on rare occasions was lung 
consolidation observed. In all experiments it was noted that the lungs increased in weight. The results shown in fig. 1 indicate that a 50 per cent. increase had occurred by the 5th day and was maintained to the end of the experiment. This increase in weight is presumably due to the production of inflammatory exudate.

\section{Histological changes}

The earliest changes are observed $24 \mathrm{hr}$ after the virus was inoculated. At this stage, only subtle changes can be detected in the bronchial mucosa and there is no inflammatory reaction. The cells lining the bronchi show a very slight increase in the eosinophilic staining of the cytoplasm, which appears a little more coarsely granular, and in some cells slightly hyaline. The nuclei show a tendency to lose their orderly basal arrangement. These changes were not observed in mock-inoculated anaesthetised mice.

At the end of the 2nd day these changes are more definite, and some cytoplasmic debris has been shed on to the epithelial surface accompanied by occasional pyknotic nuclei (fig. 2). A very small number of polymorph neutrophils can be seen in the bronchial wall or in the lumen. Occasional neighbouring blood vessels show a little margination of leucocytes (fig. 3).

On the 3rd day the changes are still almost exclusively in the bronchi, in the accompanying arteries and small blood vessels and in the immediately adjacent connective tissues. No gross structural changes are seen in the lungs and there is no apparent change in the terminal airways or alveoli. The connective tissues binding the bronchi and arteries show inflammatory oedema with a high percentage of polymorphs but no fibrin threads (fig. 4). The bronchial cavities now contain numbers of polymorphs that show very severe pyknosis and disintegration of nuclear material. The lining epithelium shows degenerative changes that are a little more severe than those observed on the 2 nd day and the walls of the bronchi show very marked infiltration of all coats by inflammatory cells. Polymorphs are again most frequent, although lymphocytes are also numerous and other inflammatory cells are present in small numbers. Very few of the mononuclear cells are pyroninophilic at this stage. The arteries also show a remarkable collection of cells on and beneath the intima, which shows some swelling of the endothelial cells. Although tightly packed, the majority of the cells seem to be polymorphs, but some may be lymphocytes and proliferating endothelial lining cells. Occasional migrating polymorphs are seen in the muscle coats of these arteries and, as the cellular collections are invariably on the juxtabronchial wall of the artery, it appears that this illustrates a very distinct chemotactic phenomenon (figs. 5 and 6).

The histological changes progress appreciably by the 5th day. The bronchial epithelium now shows severe degenerative change with much cell debris appearing in the lumina of the bronchi, where pyknotic polymorphs are now abundant. The epithelial lining cells show a ragged inner margin with granularity and vacuolation of cytoplasm, and there is clear evidence of early regeneration. The peribronchial and periarterial cuffing of inflammatory cells is intense (fig. 7). The cells of this infiltration are predominantly mononuclear, 
the majority apparently being large lymphocytes that are highly pyroninophilic. Polymorphs, however, are still numerous although somewhat dispersed in neighbouring connective tissue planes, and it is these cells that have exclusively migrated into the lumen of the bronchi. In the adjacent lung, the interstitial connective tissue and alveolar walls appear thickened and infiltrated by the inflammatory cells, but nowhere are there any typical foci of alveolar pneumonic consolidation (fig. 8).

The lesions on the 10th day show that cellular collections in the region of the arterial intima have virtually disappeared leaving intimal lining cells a little plumper and more numerous than normal. Some bronchial walls show a regular epithelial lining, but the majority still show evidence of severe degeneration and regeneration. Loss of cilia is extensive and an occasional patch of prickle-cell squamous metaplasia is seen. In some lesions the peribronchial and perivascular infiltrations are very marked and overwhelmingly lymphocytic in appearance; the features are virtually those of "lymphoid hyperplasia" (fig. 9). Interstitial thickening and inflammatory infiltrate are now more widespread with polymorphs predominating here; patchy intra-alveolar oedema and haemorrhage are seen, but there are no definite patches of pneumonic exudate.

On the 13th day the bronchi still show an excessive infiltration of predominantly mononuclear cells of the lymphoid type, but many of these possess an abundant well-stained cytoplasm and eccentrically placed nuclei. A high proportion of these infiltrating cells are still pyroninophilic. The lining epithelium of many bronchi now shows a more regular columnar appearance with basally set nuclei and ciliated surface. However, many other bronchi still show evidence both of the former damage and of regeneration. Flattened squamous metaplastic lining is seen along some stretches of mucosa (fig. 10), and occasional sections show some irregular proliferation of bronchial epithelium into the alveolar spaces. Polymorphs seem to have disappeared entirely from the bronchial lumina and are decidedly less numerous in the tissues around the bronchi and blood vessels. Some collections of large foamy macrophages are seen in the vicinity of bronchi and blood vessels. These collections and the irregular epithelial proliferation become more prominent by the 18 th and 21 st days.

The picture on the 33rd day reveals that, although the bronchial mucosa has reverted to a normal pattern, there is still appreciable focal mononuclear peribronchial cellular infiltration (fig. 11). The more diffuse inflammatory infiltration that was present and had extended into the adjacent lung framework has been reduced to trivial proportions and the lung alveolar fields are virtually normal.

No organisms are seen in the haematoxylin and eosin sections; Gramstained sections reveal no bacteria at any stage of the infection.

\section{Virus growth}

The results obtained by virus assay of the lung suspensions are shown in fig. 1. It can be seen that good virus growth occurred; maximum concentrations 


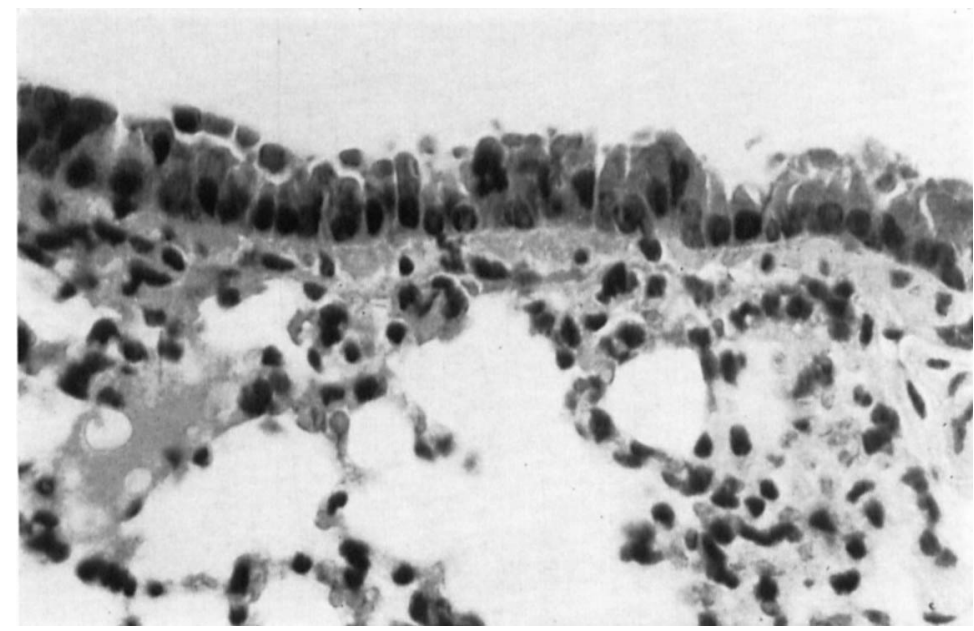

FIG. 2.-Lung 2 days after infection. Some mucosal cells show nuclear pyknosis and early disintegration of the cytoplasm. Haematoxylin and eosin. $\times 300$.

FIG. 3.-Lung 2 days after infection. There is similar epithelial damage, some polymorph infiltration of the muscle coat of the bronchus, and some leucocytic margination in the adjacent vessel. HE. $\times 280$.
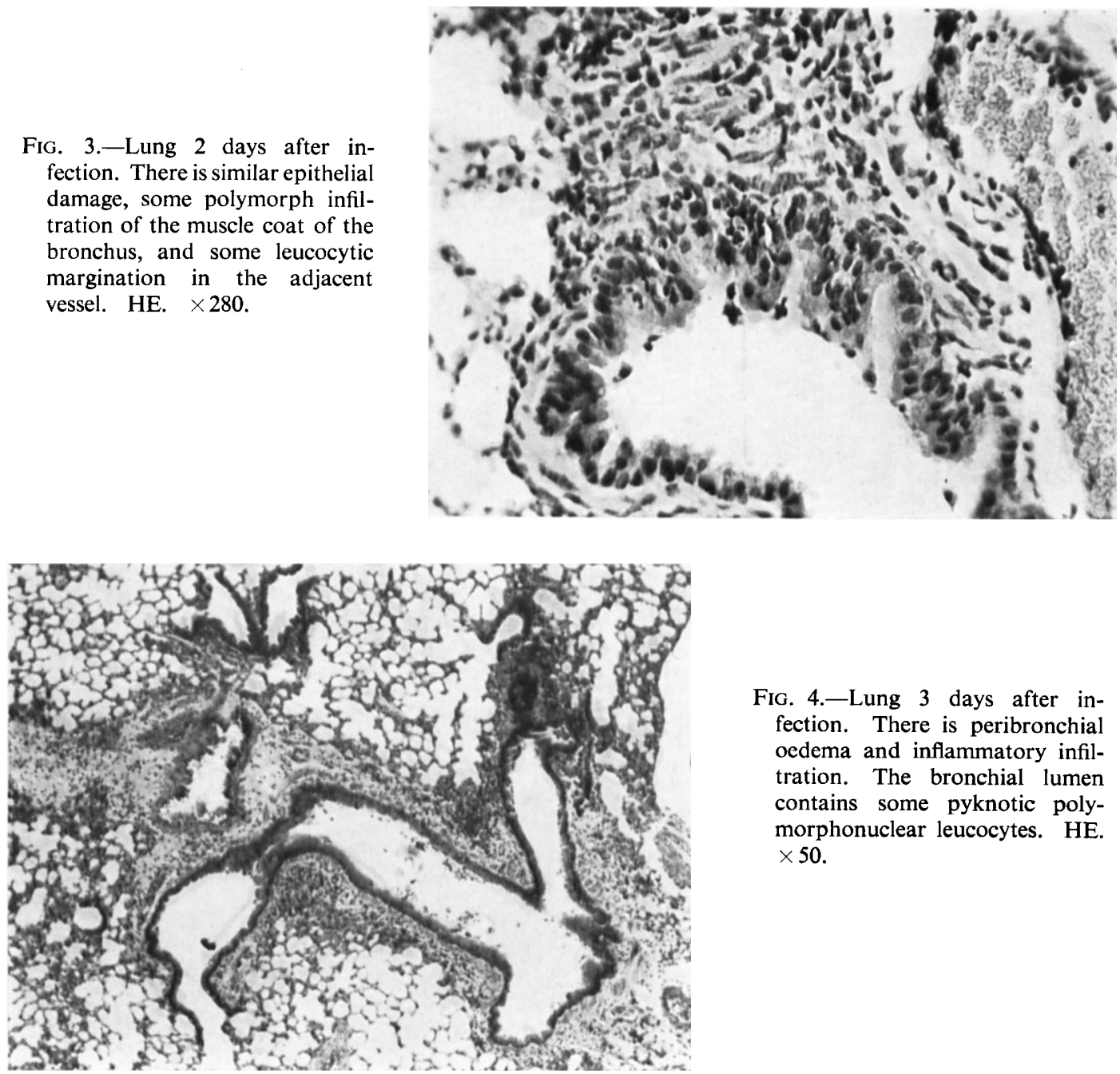

FIG. 4.-Lung 3 days after infection. There is peribronchial oedema and inflammatory infiltration. The bronchial lumen contains some pyknotic polymorphonuclear leucocytes. HE. $\times 50$. 
SENDAI VIRUS INFECTION IN MICE

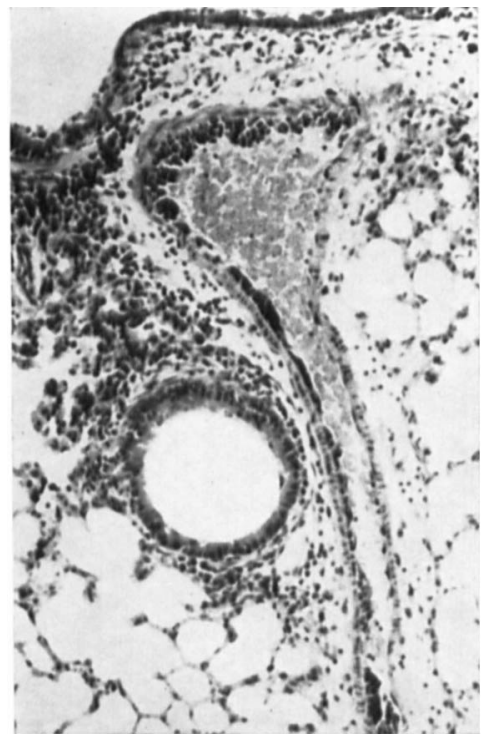

FIG. 5.-Lung 3 days after infection, showing an artery in which there is an accumulation of cells, mainly polymorphs, in the region of the intimal lining on the bronchial side of the vessel. Most of the cells are still in the lumen of the vessel. HE. $\times 135$.

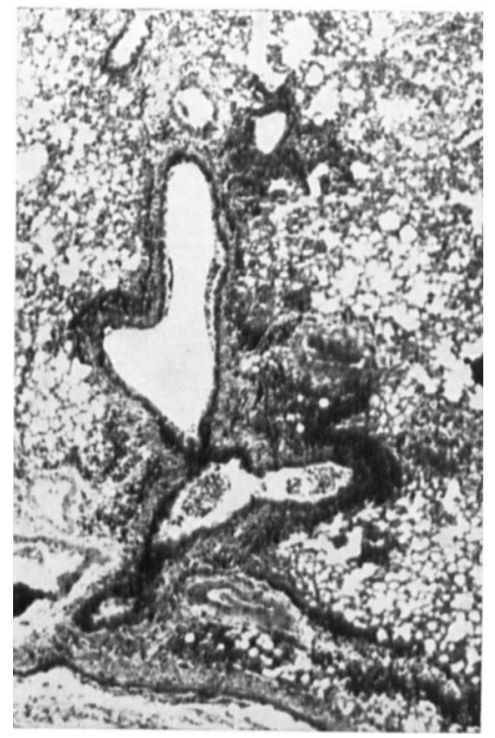

FIG. 7.--Lung 5 days after infection. There are very intense infiltrations, now mainly mononuclear, in the bronchial walls. The polymorphs are tending to spread into adjacent lung connective tissue. HE. $\times 36$.

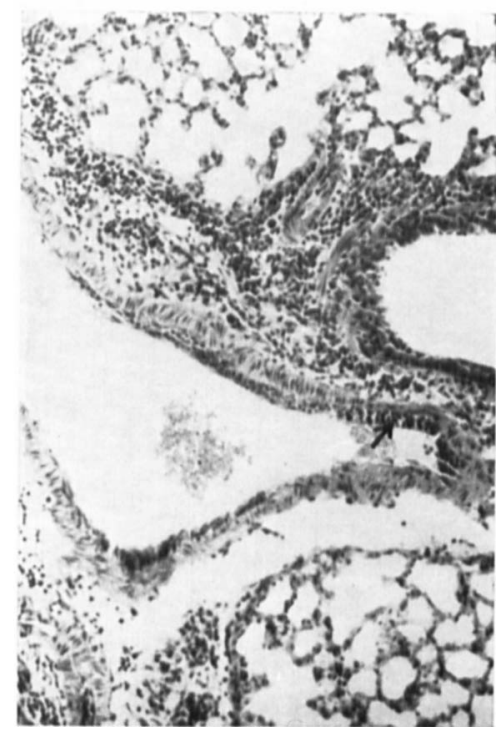

Fig. 6.-Lung 3 days after infection, showing a similar collection of cells which, in the region of the arrow, appear just outside the endothelial lining. HE. $\times 120$.

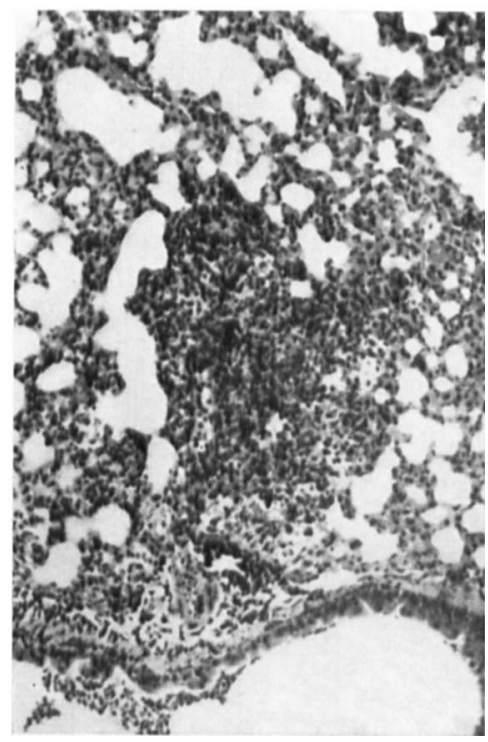

FIG. 8.-Lung 5 days after infection, showing more clearly the polymorph infiltration in adjacent lung. $\mathrm{HE}$. $\times 120$. 


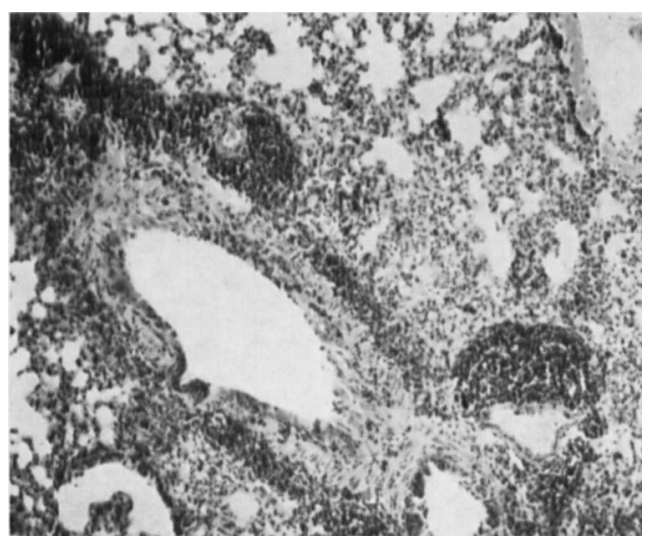

FIG. 9.-Lung 10 days after infection. Lymphoid-like clumps of small mononuclear cells are aggregated around the bronchi. HE. $\times 90$.

FIG. 10.-Lung 13 days after infection, showing the regenerated squamous epithelial bronchial lining. HE. $\times 210$.
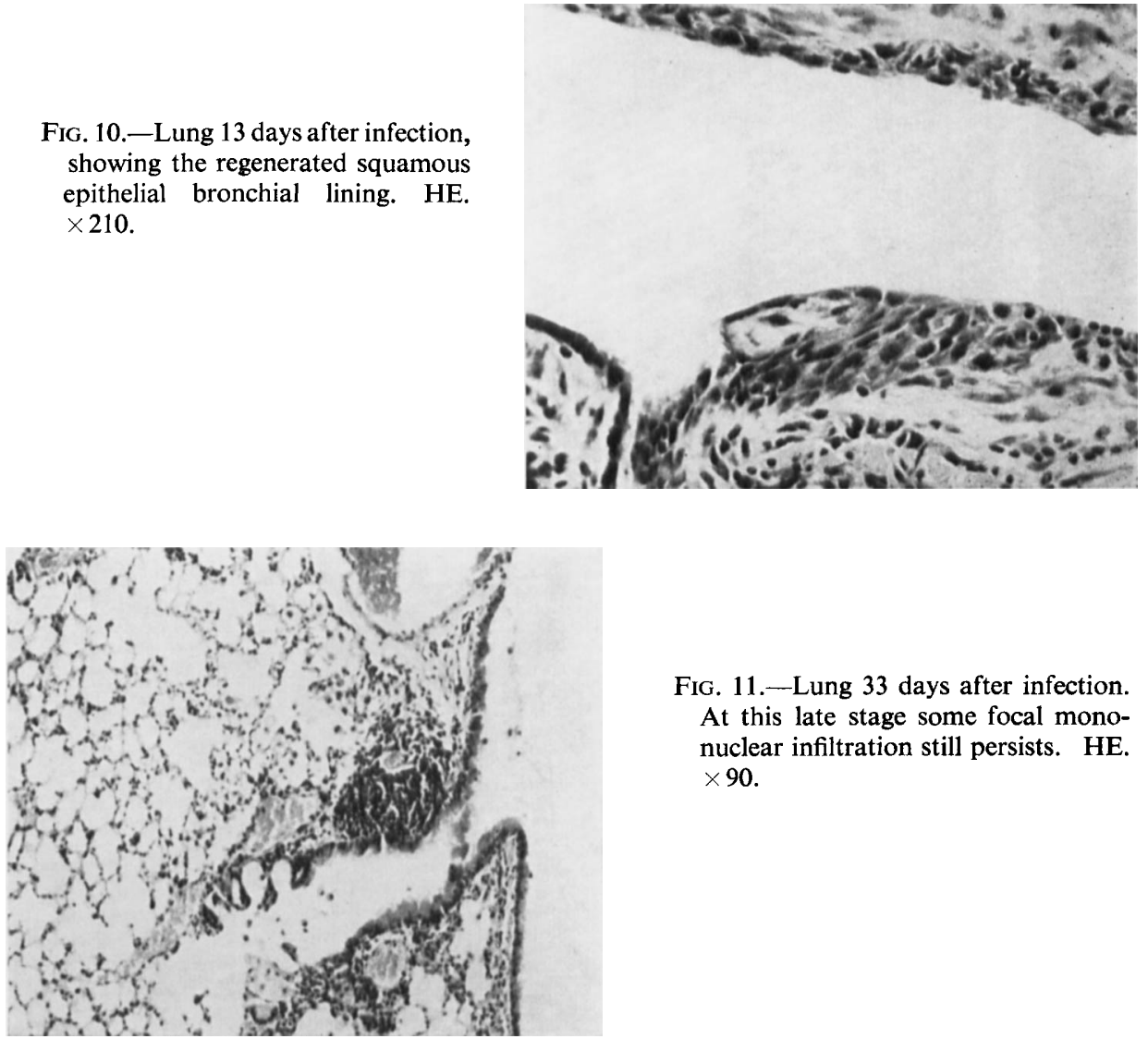

FIG. 11.-Lung 33 days after infection. At this late stage some focal mononuclear infiltration still persists. HE. $\times 90$. 
were observed on the 3rd day of the infection and the virus persisted until the 8th day. In this, and in all other experiments, we consistently failed to detect virus in the lung after the 8th day.

\section{Interferon production}

Fig. 1 shows that interferon was first detected in the lungs soon after the appearance of virus. The concentrations were usually at their highest level on the 5th day after infection and then declined as the virus disappeared.

\section{Antibody production}

Fig. 1 also shows that detectable serum antibody did not appear until the 7th day after infection, at a time when the virus had practically disappeared. The level of serum antibody rapidly rose after this, and was detectable in dilutions up to 1 in 256 on the 14th day. In comparable tests with the lung suspensions, similar curves were obtained although the titres were generally lower than those of the sera.

\section{White cell counts}

In the experiment shown in fig. 1, the infection produced a fairly rapid depression in the white cell count and the count then rose to above the preinfection level. There was some variation in the pattern of the white cell response in the various experiments, but an initial depression was nearly always seen.

\section{DisCUSSION}

The changes observed in the lungs of these Sendai-infected mice closely resemble the changes produced by unadapted influenza viruses in the same animals (Mulder, 1960). In the present study, virus replication had begun within $24 \mathrm{hr}$ of infection and had reached its peak by the 5th day. Since the cells of the bronchial mucous membrane were showing degenerative changes from the 1st day, it is reasonable to assume that the virus was replicating in these cells and that it was the replication of the virus that was responsible for the damage to these cells. However, it must be remembered that, in sensitised animals, large doses of non-replicating myxoviruses can produce similar lesions of the mucous membrane (Ogasawara, Aida and Nagata, 1961; Tong and Fong, 1964). It seems unlikely that such a mechanism was responsible in the present system since the inoculum contained less than 2 haemagglutinating units of virus.

The mechanisms concerned in the production of the inflammatory response to the mucous membrane infection are undoubtedly complex. The early polymorphonuclear response is presumably induced by products from the damaged mucous membrane cells, since it is not generally considered that viruses have chemotactic properties. However, it should be noted that the peak of the polymorphonuclear response occurred some $48 \mathrm{hr}$ before extensive visible damage of the mucous membrane was observed (see fig. 1). The delayed and 
more prolonged mononuclear response is the dominant feature of the tissue reaction. Some of these cells could be part of the general inflammatory response to the damaged mucous membrane, but the presence of pyroninophilic cells indicates that others are immunocytes induced by viral antigens. It is well established that lymphocytes have an essential role in the production of antibodies and that when these cells are stimulated by Sendai virus they produce large quantities of interferon (Gresser, 1961). Their presence in close proximity to the infected bronchioles suggests that they have an important part to play in the elimination of virus. Results of some preliminary experiments in which we have reduced the degree of mononuclear cell infiltration with immunosuppressant drugs have strengthened this view (Robinson, Cureton and Heath, to be published).

The antibody and interferon responses in this system closely resemble those observed by others who have studied influenza virus infections of the same species (Isaacs and Hitchcock, 1960). In our studies we also found that the concentration of virus started to fall immediately after interferon had reached its maximum concentration. We also found that virus had virtually disappeared by the time that antibody was first detected in the serum and lungs. These findings suggest that interferon is mainly responsible for the elimination of virus from the lungs. However, the appearance of pyroninophilic cells amongst the mononuclear cells at the 5th day possibly indicates that sufficient local antibody had been produced early enough to have played some part in the virus clearing process.

The results obtained with this system have been consistently reproducible, and this makes it suitable for studies of defence factors involved in respiratory infections. In this system the pathological changes predominantly involved the mucous membrane and submucosa and this is unlike most infections produced by mouse-adapted strains of influenza virus, which usually progress to lung consolidation and death. Because of this, it may prove to be a more useful model of the common acute viral infections of man.

\section{SUMMARY}

Sendai virus replicates well in the lungs of mice, where it produces extensive damage to the mucous membrane, but no obvious clinical illness. Rapid elimination of virus from the lungs commences after the 5th day of the infection and is associated with a mononuclear response, interferon production and antibody formation. The relative significance of these factors in terminating the infection is discussed.

We would like to thank Miss G. V. Martin and Mr J. W. Miller for their excellent technical assistance.

\section{REFERENCES}

ANDrewes, C. H., Laidlaw, P. P., AND 1934. Lancet, 2, 859.

SMITH, W.

Briody, B. A., CASSEll, W. A., AND 1955. J. Immunol., 74, 41.

Medill, Mary A. 
Cook, M. Katherine, Andrewes, B. E., 1959. Amer. J. Hyg., 69, 250.

FoX, H. H., Turner, H. C., James,

W. D., AND Chanock, R. M.

Craighead, J. E., Cook, M. Katherine, 1960. Proc. Soc. Exp. Biol. Med., 104, 301. and Chanock, R. M.

Fukumi, H., Nishikawa, F., and Kita- 1954. Jap. J. Med. Sci. Biol., 7, 345. YAMA, $T$.

GRESSER, I.

961. Proc. Soc. Exp. Biol. Med., 108, 799.

IsAACS, A., AND HitchCOCK, Griselda . 1960. Lancet, 2, 69.

MULDER, J.

1960. Ciba Fdn Study Grps, 4, 43.

Ogasawara, K., Aida, M., and Nagata, 1961. J. Immunol., 86, 599. I.

Reed, L. J., And Muench, H. 1938. Amer. J. Hyg., 27, 493.

StUart-Harris, C. H. . . . 1965. Influenza and other virus infections of the respiratory tract, 2nd ed., London,

Tong, M. J., AND FonG, J. - 1964. J. Immunol., 93, 35. 